\title{
KARAKTERISTIK ETNOMATEMATIKA SUKU NUAULU DI MALUKU PADA SIMBOL ADAT CAKALELE
}

\author{
Ethnomathematematic Charateristics of Nuaulu Tribe \\ in The Traditional Symbol of Cakalele \\ Patma Sopamena $^{1 *}$, Fahruh Juhaevah ${ }^{2}$ \\ ${ }^{1,2}$ Program Studi Pendidikan Matematika, Institut Agama Islam Negeri (IAIN) Ambon \\ Jln. Dr. H. Tarmizi Taher Kebun Cengkeh Batu Merah Atas, Ambon, Indonesia \\ e-mail: 1* patma.sopamena@iainambon.ac.id ; 2 fahruhjuhaevah@gmail.com \\ Corresponding author*
}

\begin{abstract}
Abstrak
Penelitian ini bertujuan untuk mendeskripsikan karakteristik etnomatematika Suku Nuaulu, Maluku khususnya pada simbol adat cakalele. Cakalele merupakan tarian adat perang yang dilaksanakan oleh semua desa adat di Provinsi Maluku. Cakalele dilaksanakan ketika pelaksanaan adat atau menyambut tamu penting. Penelitian ini dilaksanakan di Desa Nuanea kabupaten Maluku Tengah dengan menggunakan desain etnografi dan analisis kualitatif. Ketua adat menjadi sumber utama dalam pengambilan data tentang simbol adat cakalele. Hasil penelitian menunjukkan bahwa pada simbol tarian adat cakalele Suku Nuaulu mengandung karakteristik etnomatematika, yaitu menghitung (penjumlahan, perkalian, pembagian, dan lain-lain) terdapat pada para pelaku cakalele dan aksesoris yang digunakannnya; pengukuran terdapat pada kain berang yang dipakai oleh para pelaku adat; merancang terdapat pada aksesoris-aksesoris yang dipakai oleh para pelaku adat; permainan terdapat pada tarian cakalele sendiri; menjelaskan terdapat pada cerita tarian cakalele dan pendukungnya; dan Locating terdapat pada tempat pelaksanaan tarian cakalele.
\end{abstract}

Kata Kunci : Karakteristik etnomatematika, suku Nuaulu, simbol adat Cakalele.

\begin{abstract}
This research aims to destribe Ethnomathematematic Charateristics of Nuaulu Tribe, especially in the traditional symbol of Cakalele dance. Cakalele is traditional war dance that carry out by all villages in Maluku Province. Cakalele are carried out when performing costums or welcoming important guests. This research was carried out in the village of Nuanea, Maluku Tengah, using ethnographic design and qualitative analysis. The customary leader was the main source of data collection on traditional cakalele symbols. The results show that on the traditional cakalele dance symbol of the Nuaulu tribe contained ethnomatematic characteristics, namely counting operations (addition, multiplication, division, etc.) found in the cakalele actors and the accessories they used; measurements are found in the berang cloth used by customary actors; designing is on accessories used by customary actors; the game is in the cakalele dance itself; it explains there are cakalele dance stories and their supporters; and the room is located at the location of the cakalele dance.
\end{abstract}

Keywords: Ethnomathematic Characteristics, Nuaulu Tribe, Traditional Symbol of Cakalele . 


\section{PENDAHULUAN}

Kekayaan budaya di Indonesia memang tak dapat diragukan lagi kuantitasnya. Setiap provinsi termasuk Maluku memiliki budaya yang tercermin dalam kebiasaan atau adat masing-masing, namun ada beberapa adat atau budaya yang hampir punah mengikuti dan sudah terkontaminasi dengan modernisasi, demikian halnya dengan budaya di Maluku. Menurut Antropolog AH Keane, Pulau Seram merupakan pulau yang tertua di Maluku, pada zaman dulu telah didiami oleh suku-suku Alifuru yang disebut oleh antropolog Keane sebagai bangsa Alfuros. Suku Bangsa Alfuros ini adalah percampuran antara bangsa Kaukasus, Mongol, dan Papua. Di Pulau Seram, Suku Bangsa Alfuros ini terkenal dengan nama suku Bangsa Alune dan Wemale. Selanjutnya antropolog Sachse dan O.D Taurn berpendapat bahwa Suku Alune berasal dari utara, kemungkinan dari Sulawesi Utara dan Halmahera, sedangkan Suku Bangsa Wemale berasal dari timur kemungkinan dari Melanesia (NN.1977/1978, Sahusilawane, 2005: 9,45; Tim Penelitian, 2007:32) dalam Wuri Handoko [19]. Maluku yang sering disebut sebagai daerah "raja-raja" juga memiliki adat atau kebiasaan dalam aktivitas kehidupan masyarakat, misalnya tarian adat cakalele. Tarian adat cakalele pada masing-masing desa adat pun memiliki ciri khas yang berbeda pula terutama pada simbol adat yang digunakan pada saat tarian adat cakalele ini dilakukan. Namun demikian pada umumnya tarian adat cakalele memiliki simbol yang universial, misalnya menggunakan parang (pedang), salawaku (perisai), dan tombak. Sedangkan ciri khusus yang digunakan umumnya adalah aksesoris-aksesoris yang menjadi hiasan bagi para pelaku adat cakalele (kapitan) yang turun temurun, misalnya; baju adat, gelang, kalung, selendang, lambang yang digunakan oleh anggota adat, dan lain-lain. Karena tarian adat cakalele merupakan tarian perang maka pasti ada pemimpin perang (komandan) dan ada yang dipimpin (prajurit). Di Nuanea pelaku adat yang tertinggi adalah ketua adat (jenderal) yang terendah disebut prajurit. Ciri-ciri khusus atau aksesoris yang dipakai oleh pelaku adat (kapitan) mengandung muatan materi matematika berupa penjumlahan, geometri, maupun basis bilangan, sehingga dalam kegiatan adat cakalele menyimpan kandungan matematika.

Menurut Musa, matematika adalah konstruksi pengetahuan berkaitan dengan hubungan kualitatif dan kuantitatif dari ruang dan waktu [14]. Matematika adalah aktivitas manusia yang berhubungan dengan pola, pemecahan masalah, berpikir logis, dan sebagainya, dengan tujuan untuk memahami dunia [8]. Matematika adalah subjek universal dalam setiap kebudayaan yang memiliki konsep angka dan gagasan bahwa $1+1=$ 2, tak peduli betapa budaya teknologi canggih. Gagasan universalitas matematika lebih diperkuat oleh fakta bahwa itu diciptakan di seluruh dunia, dalam banyak tempat dan waktu yang berbeda, dengan sedikit atau tidak ada kontak antara penciptanya. Menurut Plato, matematika adalah alat yang handal untuk mengejar kebenaran [16]. Heather (2003) dan Kanh (2003) menegaskan bahwa belajar matematika mengharuskan manusia untuk mengembangkan cara berpikir matematis [6]. Selanjutnya, John menegaskan bahwa ada persepsi tentang matematika adalah alat yang efektif untuk menganalisis, meneliti dan memverifikasi kebenaran [7]. Kehidupan manusia tetap tidak lengkap tanpa matematika [21], sehingga matematika sangat berperan aktif dalam aktivitas masyarakat sehari-hari tidak terkecuali kehidupan budaya masyarakat.

Etnomatematika mengacu pada studi praktek matematika dari kelompok budaya tertentu di bidang yang berkaitan dengan masalah lingkungan dan kegiatan [13]. Dengan awalan "etno" mengacu pada mengidentifikasi kelompok budaya, seperti suku masyarakat nasional, kelas profesional dan lain-lain dan termasuk bahasa mereka dan praktek sehari-hari. "Mathema" di sini berarti untuk menjelaskan, memahami dan mengelola realitas khusus dengan menghitung, mengukur, mengklasifikasi, order dan pola pemodelan yang muncul di lingkungan. Akhiran "ticks" berarti seni untuk teknik. Etnomatematika adalah studi cara matematika yang digunakan oleh kelompok-kelompok budaya yang diidentifikasi dalam memahami, menjelaskan, dan mengelola masalah dan kegiatan yang timbul dalam domain sendiri [18].

Bishop menyimpulkan ada enam aktivitas matematis yang bersifat universal yang bisa ditemukan pada setiap kelompok budaya yaitu: Counting, Locating, Measuring, Designing, Play, dan Explaining CLMDPE [20]. Keenam aktivitas ini menjadi dasar dalam pengembangan matematika yang kemudian dikenal sebagai karakteristik etnomatematika [20]. Penelitian ini mendeskripsikan karakteristik Designing, yaitu aktivitas designing berkaitan dengan pembuatan pola untuk membuat objek-objek atau artefak budaya yang digunakan di rumah, dalam perdagangan, dekorasi, berperang, permainan, dan tujuan keagamaan. Designing juga berkaitan dengan hal-hal yang berskala besar seperti rumah, perkampungan, jalan, kebun, lapangan, desa, dan kota. Semua ini menjadi sumber dan bagian dalam pembentukan pengetahuan matematika anggota kelompok budaya. 
Etnomatematika telah diteliti diantaranya oleh Ahmet Küçük [2]. Küçük meneliti etnomatematika di Anatolia Turki yang berkaitan dengan makna matematika dari artefak-artefak di Anatolia [2]. Selanjutnya penelitian yang dilakukan oleh Patma Sopamena [15] meneliti tentang etnomatematika masyarakat Maluku Tengah dan Kota Ambon dalam menjalani kehidupan sehari-hari: pemikiran matematika dalam multikulturalisme [15]. Abdullah, A. S. meneliti Ethnomathematics in Perspective of Sundanese Culture [1]. Penelitian yang lain juga dilakukan oleh Wara Sabon Dominikus tentang etnomatematika Suku Adonara di Nusa Tenggara Timur [20]. Chatarina Febriyanti, dkk., meneliti etnomatematika pada permainan tradisional engklek dan gasing khas kebudayaan Sunda [5].

Dari beberapa hasil penelitian di atas dan kajian etnomatematika itu sendiri, yang bersifat unik dan berbeda untuk setiap daerah. Oleh karena itu, penelitian ini mengkaji etnomatematika Suku Nuaulu Maluku difokuskan pada kajian etnomatematika berupa simbol adat cakalele yang terdapat pada simbol adat cakalele berupa aksesoris yang dipakai oleh para pelaku adat pada saat melakukan tarian cakalele.

\section{METODE PENELITIAN}

\subsection{Tipe Penelitian}

Penelitian ini termasuk penelitian kualitatif-eksploratif yaitu untuk mengeksplorasi, mengidentifikasi, dan mendeskripsikan berbagai pengetahuan matematika dalam budaya Nuaulu. Desain penelitian yang digunakan adalah desain etnografi, karena sesuai dengan masalah dan tujuan penelitian. Dengan desain etnografi dapat dideskripsikan budaya Nuaulu dan selanjutnya dapat diungkapkan dan dideskripsikan pengetahuan matematika yang terkandung di dalamnya. Hal ini didasarkan pada pemikiran bahwa setiap budaya mengembangkan matematika (pengetahuan matematika) yang berbeda sesuai dengan kebutuhan masyarakatnya.

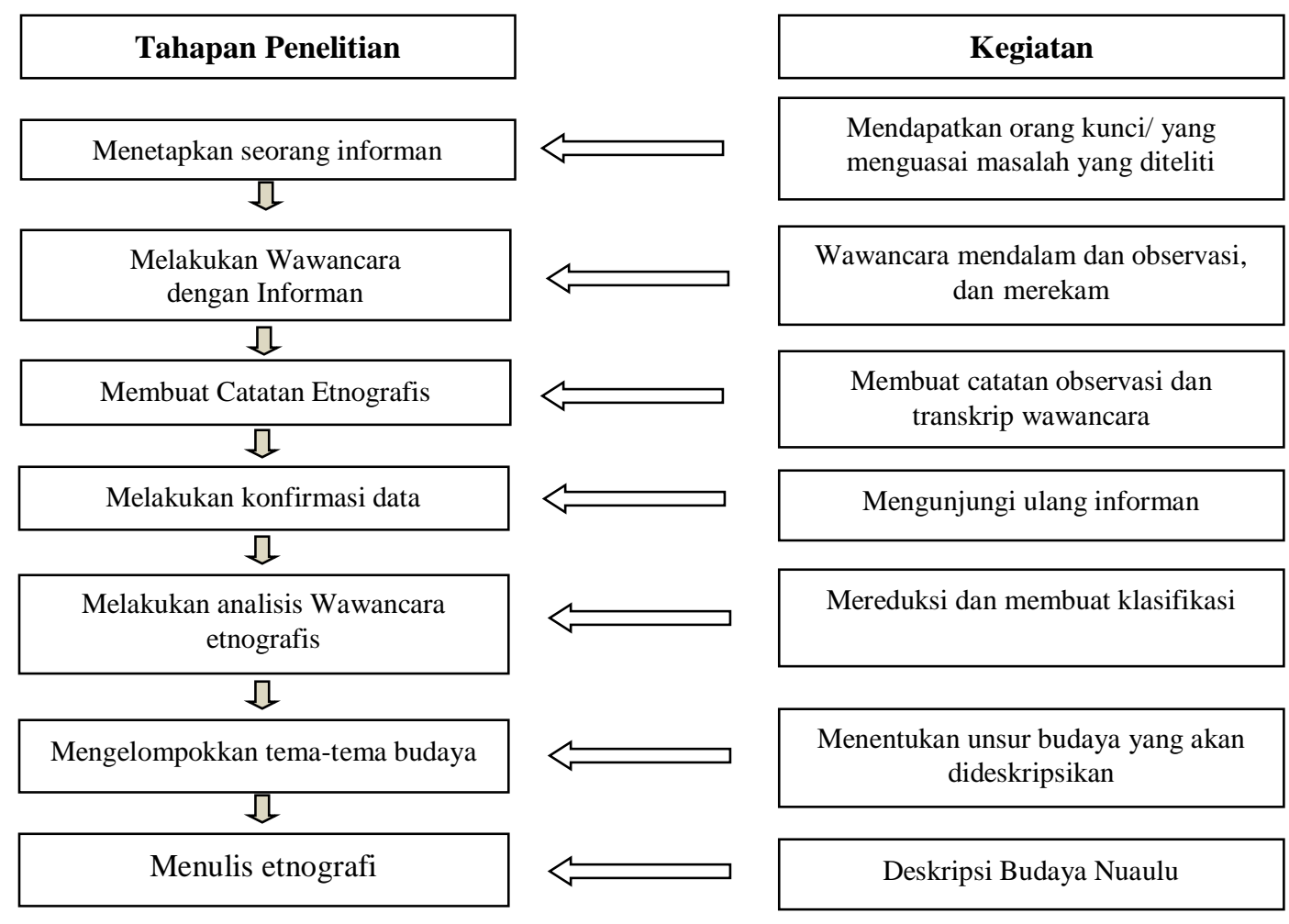

Gambar 1. Langkah APMB (Modifikasi Spradley, 2007)

Penggunaan metode penelitian etnografi mengacu pada metode penelitian etnografi yang baru dari Spradley yang dikenal dengan Alur Penelitian Maju Bertahap-APMB (The Developmental Research Sequence). APMB terdiri dari 12 langkah dan harus diikuti secara ketat dan terurut mulai dari langkah pertama hingga langkah keduabelas. Keduabelas langkah APMB secara berturut-turut sebagai berikut: menetapkan informan, mewawancarai informan, membuat catatan etnografi, mengajukan pertanyaan deskriptif, melakukan analisis wawancara, membuat analisis domain, mengajukan pertanyaan terstruktur, 
membuat analisis taksonomi, mengajukan pertanyaan kontras, membuat analisis komponen, menemukan tema-tema budaya, dan menulis suatu laporan etnografi ( [9]; [10]). Walaupun peneliti tidak mengikuti keduabelas langkah penelitian secara berurutan, namun deskripsi tentang budaya Nuaulu menggunakan kerangka etnografi sebagaimana dijelaskan di atas yang mencakup hampir semua komponen dalam langkah APMB (Alur Penelitian Maju Bertahap). Sebagaimana terlihat dalam Gambar 1 di atas.

\subsection{Subjek Penelitian}

Penelitian ini dilakukan di Desa Nuanea yang terletak di Kabupaten Maluku Tengah Provinsi Maluku. Untuk mendapatkan data sesuai permasalahan penelitian maka subjek penelitian yang merupakan salah satu sumber data harus memenuhi beberapa kriteria antara lain: (1) mereka yang menguasai atau memahami apa yang diteliti; (2) mereka yang termasuk orang yang sudah atau sedang terlibat pada kegiatan yang diteliti; (3) mereka yang mempunyai waktu memadai untuk dimintai informasi [16]. Selain itu dalam memilih subjek penelitian sebagai sumber data perlu mempertimbangkan hal-hal berikut: (1) orang yang bersangkutan memiliki pengalaman pribadi yang sesuai dengan permasalahan yang diteliti; (2) usia orang yang bersangkutan telah dewasa; (3) orang yang bersangkutan sehat jasmani dan rohani; (4) orang yang bersangkutan bersifat netral, tidak mempunyai kepentingan pribadi tertentu; (5) orang yang bersangkutan memiliki pengetahuan yang luas mengenai permasalahan yang diteliti [11]. Lebih lanjut dikatakan bahwa dalam penelitian kualitatif lokasi penelitian dan individu sebagai sumber data dipilih dengan sengaja dan terencana agar dapat membantu peneliti memahami masalah yang diteliti [10].

Subjek dalam penelitian ini subjek adalah tua adat dan masyarakat Nuaulu yang sudah usia lanjut. Berdasarkan kriteria subjek di atas maka telah dipilih 4 orang. 1 orang tua adat (Bapak Apinea Matoke) dan 3 orang masyarakat Nuanea.

\subsection{Instrumen Penelitian}

Instrument utama penelitian ini adalah peneliti sendiri yang dilengkapi dengan instrumen pendukung atau pelengkap berupa panduan observasi, panduan wawancara, handycam, dan kamera [11]. Peneliti sebagai instrument utama berfungsi menetapkan fokus penelitian, memilih subjek penelitian sebagai sumber data, melakukan pengumpulan data, menilai kualitas data, menganalisis data, menafsirkan data, membuat simpulan penelitian, dan akhirnya membuat laporan penelitian. Peneliti sebagai instrumen utama dalam penelitian kualitatif karena beberapa pertimbangan [10].

\subsection{Teknik Analisa Data}

Analisa data dalam penelitian ini sesungguhnya dilakukan sejak sebelum ke lokasi penelitian, selama pengumpulan data, dan setelah pengumpulan data. Analisa data sebelum ke lokasi penelitian dilakukan terhadap data hasil studi pendahuluan atau data sekunder lain yang digunakan untuk menentukan fokus penelitian dan subjek penelitian. Fokus penelitian ini masih bersifat sementara dan akan berkembang setelah peneliti ke lokasi penelitian dan selama di lokasi penelitian. Analisis data merupakan proses yang membutuhkan refleksi terus-menerus terhadap data, mempertanyakan keabsahan dan kebenaran data, dan menulis catatan singkat selama penelitian. Secara umum analisis data terdiri dari tiga tahap dimulai dengan menyiapkan dan mengorganisir data (data teks seperti transkrip dan data gambar seperti foto) untuk analisis, dilanjutkan dengan mereduksi data tersebut menjadi tema melalui proses pengodean dan peringkasan kode, dan terakhir menyajikan data dalam bentuk bagan, tabel, dan pembahasan [12].

\section{HASIL DAN PEMBAHASAN}

Dalam beberapa budaya Nuaulu desa Nuanea ini ditemukaan bagaimana orang Nuaulu bermatematika dalam aktivitas kehidupan sehari-hari. Di samping itu ditemukan juga berbagai konsep matematika yang dapat disebut sebagai matematika tersembunyi (hidden mathematics) atau matematika beku (frozen mathematics) dalam budaya Nuaulu. Tulisan ini mendeskripsikan hidden mathematics pada aktivitas adat cakalele yang dikhususkan pada aksesoris-aksesoris yang dipakai oleh para kapitan.

Cakalele pada suku Nuaulu desa Nuanea merupakan suatu tarian adat yang dilakukan untuk keperluan adat, misalnya prosesi dalam membangun rumah adat Matoke yang berjumlah 3 bangunan, prosesi pelantikan raja, penyambutan tamu penting, dan lain-lain. Aksesoris-aksesoris yang dipakai oleh para 
kapitan disimpan di rumah ada Matoke dan akan digunakan ketika ada acara adat cakalele atau tarian maku-maku.

\subsection{Hitungan}

Pada ritual adat yakni aktivitas ritual pemakaian kain berang, maku-maku, dan cakalele maupun aksesoris para pelaku adat terdapat konsep matematika yang tersembunyi (hidden mathematics).

M : Ada banyak si kalau marga adat. Ada sekitar dalapang marga (ada banyak, sekitar delapan marga)

$\mathrm{P}$ : Apa-apa itu pak,, kalau beta boleh tau?

M : Ada Latoge, Sonawe, Bia, Kemolait, Soumori, Huri. Masing masing soa itu akang pung rumah adat dua. (ada Latoge, Sonawe, Bia, Kemolait, Soumori, Huri, masing-masing marga adat memiliki dua rumah adat)

$\mathrm{P}:$ : Apa-apa itu tete. (apa itu aki)

$\mathrm{M}$ : Akang nama rumah tua deng rumah kapitan (Namanya rumah tua dan rumah kapitan)

$\mathrm{P}$ : Itu rumah tua par apa? Rumah kapitan par apa? (apa fungsi dari rumah tua dan rumah kapitan?)

M : Rumah tua itu kalau ada orang kaweng tu biking di situ, trus rumah kapitan tu par bantu rumah tua. (fungsi rumah tua itu ketika ada yang mau nikahan, selanjutnya rumah kapitan untuk membantu rumah tua)

Selanjutnya jumlah manik-manik yang menambah aksesoris pada ritual adat pemakaian kain berang juga berdasarkan patalima dan patasiwa. Masing-masing orang laki-laki akan dipakaikan manik-manik oleh sang guru dengan banyaknya gelang atau kalung yang disanggupi oleh orang tuanya. Sebagaimana pernyataan kepala adat Matoke sebagai berikut.

M : Nanti dong guru lipat baru kasih pake akang ka dia ana murid itu. Jadi nanti dong ada lima orang atau lebih bantu dia pung tamang par pi tangkap kusu par kasih par dia pung guru baru guru mulai kasih dia pung berang, cawat, baju adat, mani-mani dan samua-samua lengkap. (gurunya yang nantinya melipat kain merah itu dan dipakaikan ke muridnya. Jadi nanti ada sekitar lima orang teman yang akan membantunya untuk menangkap "kus-kus" untuk diberikannya kepada guru, selanjutnya guru tersebut memasang kain merah, cawat, baju adat, manik-manik, dan semuanya lengkap.)

$\mathrm{P}$ : Kalu, manik-manik itu misalkan satu orang musti pake barapa? (berapa banyak manik- manik yang mesti dipakai setiap orang?)

M : Zg,,, orang tua yang cari. Ha kalau gelang itu laeng lai,,, harus ada 10 lai, 5 di sabalah, 5 lai disabalah. Manik-manik pake salempang jaga sama. Begitupun dengan cincin, harus 10 lai, 5 sabalah, 5 sabalah. (tidak, orang tuanya yang mencarikannya. Kalau gelang itu juga lain, harus ada 10 juga, 5 di sebelah kiri dan 5 di sebelah kanan. Manik-manik yang dipakai sebagai salempang juga sama. Begitupun dengan cincin, harus 10 juga, 5 di sebelah kanan dan 5 di sebelah kiri.)

Berdasarkan pernyataan-pernyataan di atas maka terdapat konsep operasi bilangan, antara lain: ada operasi penjumlahan, perkalian, dan pecahan. Misalnya ada 7 marga adat, dengan 8 rumah adat yang terdiri dari 2 rumah adat untuk marga Matoke/kepala adat $(2 \times 1=2)$ dan 1 rumah untuk masing-masing marga kapitan $(1 \times 6=6)$. Selanjutnya untuk 1 orang laki-laki yang akan beranjak dewasa dibantu oleh 5 orang teman untuk menunjukkan "kejantan" menangkap binatang "kus-kus" jadi jika 3 orang maka 3 x $5=15$ orang. Sedangkan pecahan terdapat pada ukuran kain berang pada anak di bawah 20 tahun sebesar setengah meter (1/2 meter). Hal ini senada dengan yang terdapat dalam [3], [4] dan [17], bahwa budaya juga merupakan aktivitas matematika masyarakat pada suatu daerah tertentu. Senada juga dengan yang dikemukakan oleh Bishop tentang aktivitas matematika secara universal yang dikategorikan sebagai karakteristik etnomatematika dengan penjelasannya bahwa terdapat enam karakteristik dari etnomatematika, yaitu Counting, Locating, Measuring, Designing, Play, dan Explaining.

Selain istilah patalima dan patasiwa terdapat juga pada setiap aksesoris-aksesoris para kapitan (terbuat dari lembaran kayu) banyaknya gambar berjumlah 7 (Gambar 4). Konstruksi konsep matematika dalam aksesoris suku Nuaulu desa Nuanea seperti pada Gambar 2, berikut: 


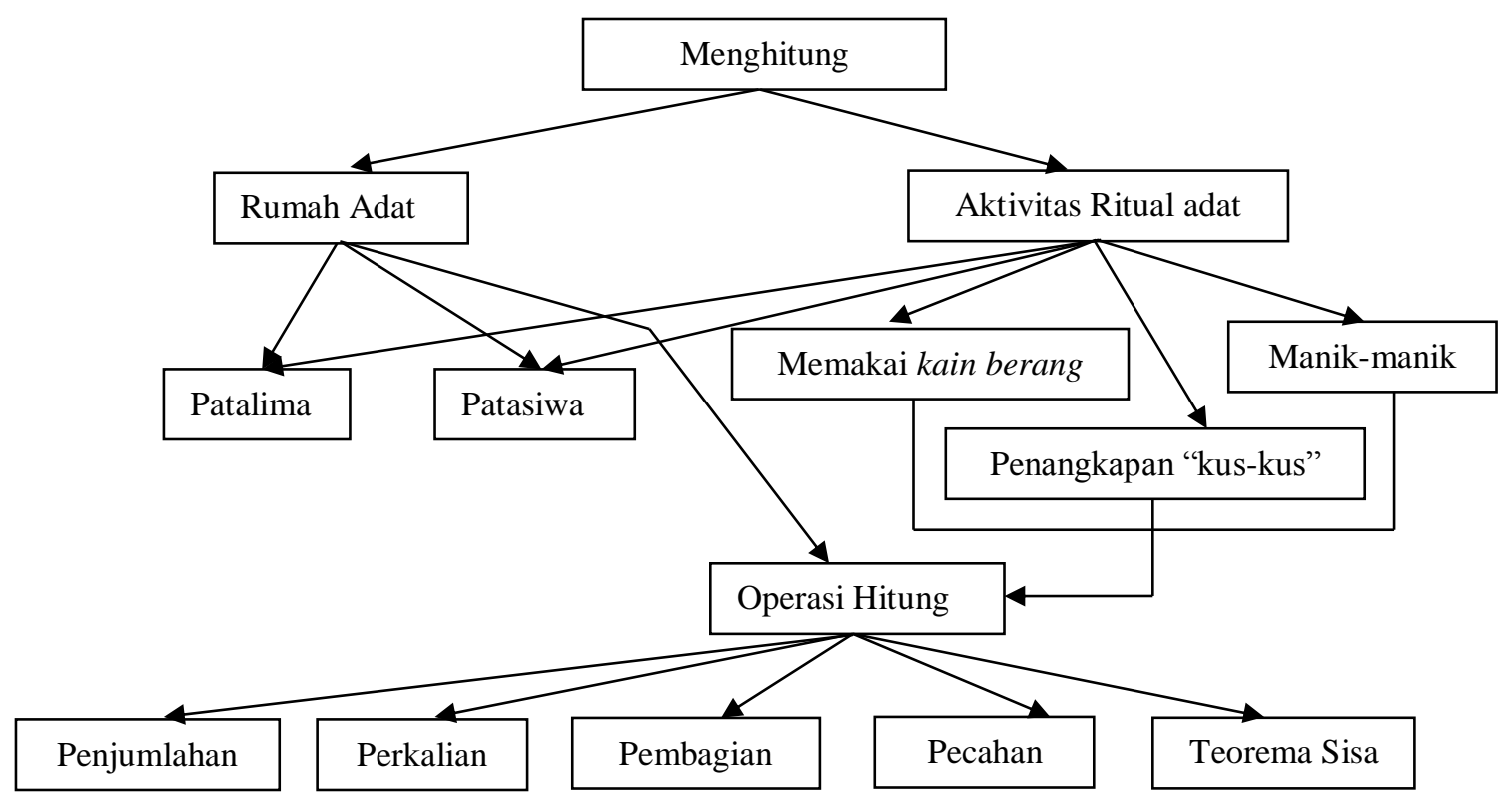

Gambar 2. Etnomatematika dalam Budaya Bercocok Tanam Suku Nuaulu

\subsection{Bentuk Geometri}

Cakalele pada Suku Nuaulu, Desa Nuanea merupakan suatu tarian adat yang dilakukan untuk keperluan adat, misalnya prosesi dalam membangun rumah adat Matoke yang berjumlah 3 bangunan, prosesi pelantikan raja, penyambutan tamu penting, dan lain-lain. Dilaksanakan terkadang setelah tarian maku-maku juga.

M : Maku-maku itu adalah katong manari baputar dalam rumah ini sampe siang kemudian katong turung di muka rumah untuk Cakalele. (maku-maku adalah kita menari berputar di dalam rumah hingga siang kemudian dilanjutkan dengan cakalele di depan rumah adat)

Hidden mathematics yang terdapat dalam tarian adat maku-maku adalah "lingkaran", mereka akan menari maku-maku sepanjang malam, bahkan informasi yang peneliti peroleh dari beberapa masyarakat di sekitar Desa Nuanea, bahwa "bisa sampai beberapa hari".

Selanjutnya aksesoris-aksesoris yang dipakai oleh para kapitan (terdapat 8 marga yang termasuk dalam kapitan, yaitu: Matoke, Latoge, Sonawe, Bia, Kemolait, Soumori, dan Huri) disimpan di rumah ada Matoke dan akan digunakan ketika ada acara adat cakalele atau tarian maku-maku.

$\mathrm{P}$ : Di sini marga yang adat ada berapa? (ada berapa marga yang termasuk marga adat?)

M : Ada banyak si kalau marga adat. Ada sekitar dalapang marga (ada banyak, sekitar delapan marga)

P : Apa-apa itu pak,, kalau bt boleh tau?

M : Ada Latoge, sonawe, Bia, Kemolait, Soumori, Huri. Masing masing soa itu akang pung rumah adat dua. (ada Latoge, sonawe, Bia, Kemolait, Soumori, Huri, masing-masing marga adat memiliki dua

rumah adat)

$\mathrm{P}:$ : Apa-apa itu tete. (apa itu aki)

$\mathrm{M}$ : Akang nama rumah tua deng rumah kapitan (Namanya rumah tua dan rumah kapitan)

Selanjutnya aksesoris yang dipakai oleh para kapitan sebagaimana Gambar 3 dan 4 berikut: 


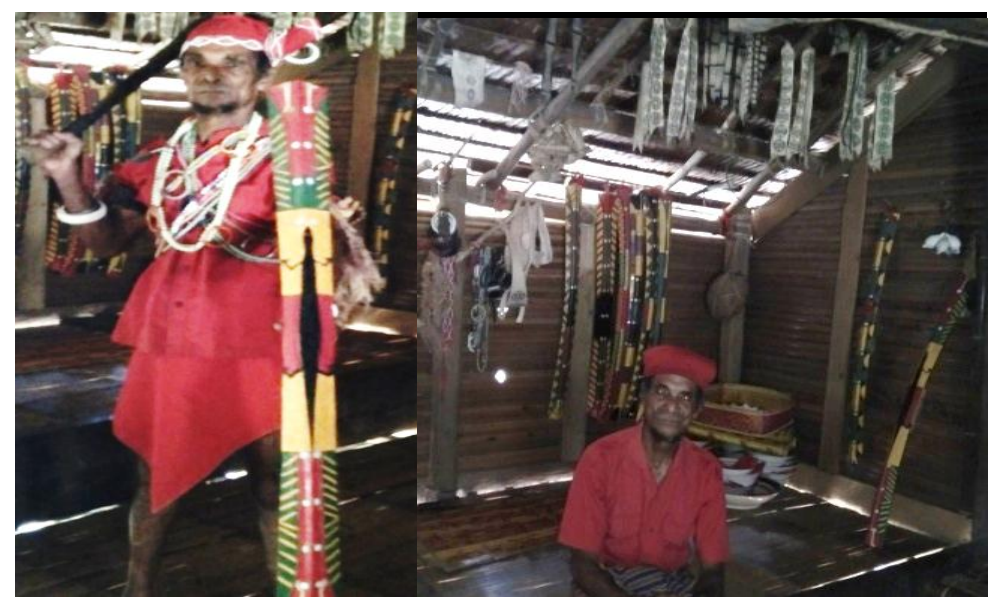

Gambar 3. Baju Adat Kepala Adat Matoke

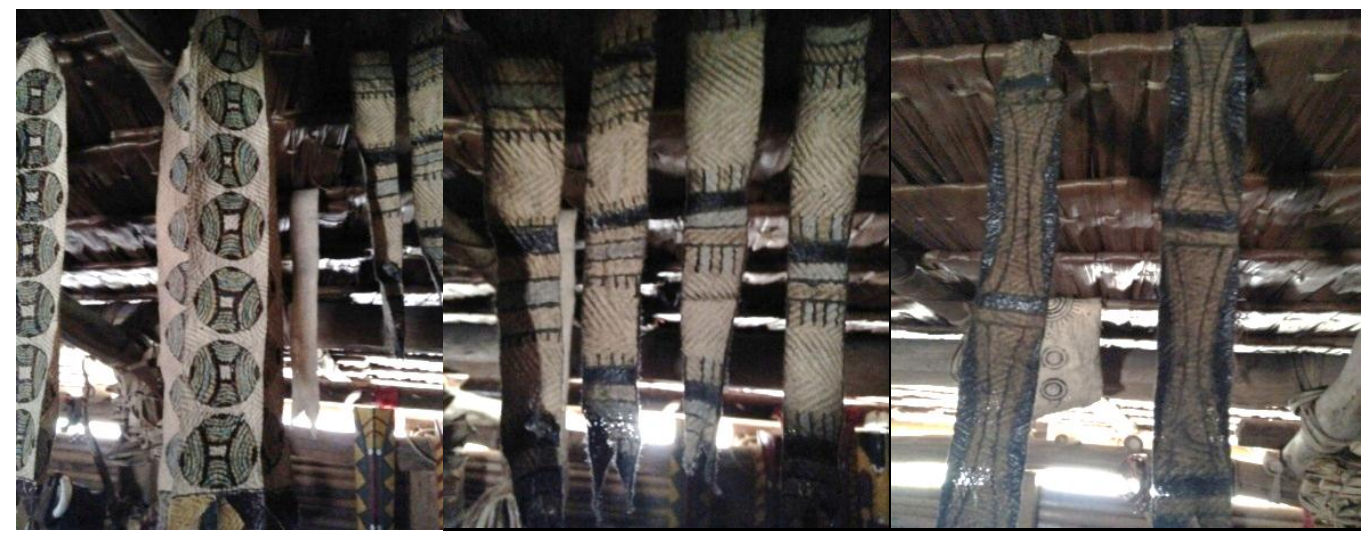

Gambar 4. Aksesoris para kapitan (prajurit)

Pada kehidupan sehari-hari, seperti diketahui dan terlihat pada identitas Suku Nuaulu pada cara berpakaian dalam aktivitas kesehariannya, bahwa setiap orang laki-laki dewasa dan anak laki-laki yang akan beranjak dewasa pasti terlihat menggunakan ikat kepala berwarna merah. Ikat kepala merah tersebut oleh masyarakat setempat atau masyarakat Maluku disebut sebagai kain berang.

Berdasarkan cerita masyarakat sekitar suku Nuaulu bahwa laki-laki yang menggunakan ikat kepala merah atau kain berang menandakan pria tersebut telah dewasa atau telah bisa bertanggung jawab. Selanjutnya untuk memperoleh kain berang sang laki-laki harus melalui ritual adat yang akan dilakukan oleh seorang guru. Senada dengan yang diungkapkan oleh Sahusilawane bahwa upacara-upacara yang khas biasanya bertalian dengan kelahiran, masa kanak-kanak, masa remaja, perkawinan hingga kematian [19]. Sebagaimana wawancara yang dilakukan oleh peneliti dan tua adat Matoke berikut.

$\mathrm{P} \quad$ : Jadi su harus siap untuk pake ini! Ini artinya apa pak (menujukkan kain pengikat kepala tua adat)

M : Ha itu dari dolo laeee musti pake kaeng berang. Macam katong di agama? (zg dengar) harus pake songko putih. (sejak dahulu kala harus memakai "kain merah". Seperti di agama Islam harus memakai kopoiah putih (kopiah haji))

P : Lalu akang pung ukuran,,, kalau maw pake,, (berapa ukurannya?)

M : Kalau umpanya lia ana tu su mulai basar berarti kasih 1 meter, tapi kalau dia masih kacil yah pake stengah meter sa,,, Lebar sama,,,, panjang sesuai pernyataan tadi. Nanti gunting akang sama-sama baru lipa pinggir-pinggir baru manjai. (jika sudah anak itu sudah mulai dewasa berarti ukurannnya bisa 1 meter, tetapi jika dia masih kecil berarti ukurannya $1 / 2$ meter saja.... Lebar dan panjangnya sama.)

$\mathrm{P} \quad$ : Lalu nanti pasangnya bagimana? (bagaimana cara memasangnya?)

M : Nanti dong guru lipat baru kasih pake akang ka dia ana murid itu. Jadi nanti dong ada lima orang atau lebih bantu dia pung tamang par pi tangkap kusu par kasih par dia pung guru baru guru mulai kasih dia pung berang, cawat, baju adat, mani-mani dan samua-samua lengkap. (gurunya yang akan melipat kain itu dan memakaikannya pada muridnya. Jadi nantinya ada lima atau lebih temannya yang membantu dia untuk menangkap binatang kus-kus untuk diberikan 
kepada guru tersebut, kemudian gurunya akan memberikan kain merahnya, cawat, baju adat, manik-manik, dan semuanya.)

Contoh ikat kepala kain berang sebagaimana yang dipakai oleh kepala adat Matoke ketika peneliti melakukan wawancara dengan beliau dan termasuk di dalam aksesoris yg dipakai oleh para kapitan pada saat cakalele (Gambar 2).

Hampir semua aksesoris adat, baik kain berang, maku-maku, maupun cakalele mencerminkan konsep geometri, terutama pada konsep bangun datar dan bangun ruang. Konsep geometri dalam aksesoris adat di atas disajikan pada Tabel 1, berikut.

Tabel 1. Konsep Geometri dalam Aksesoris Cakalele

\begin{tabular}{|c|c|c|c|c|}
\hline No & Aktivitas adat & Bentuk geometri & Jumlah & Nama \\
\hline 1 & $\begin{array}{l}\text { Tarian maku- } \\
\text { maku }\end{array}$ & & $\begin{array}{l}8 \text { (1 kepala adat }+7 \\
\text { kapitan/prajurit) }\end{array}$ & Lingkaran \\
\hline 2 & Kain berang & & $\begin{array}{l}\text { - } \quad 1 \mathrm{~m} \text { untuk dewasa } \\
\text { - } \quad 1 / 2 \mathrm{~m} \text { untuk remaja }\end{array}$ & $\begin{array}{l}\text { Persegi (lebar dan } \\
\text { panjangnya sama) }\end{array}$ \\
\hline \multirow{3}{*}{3} & \multirow{3}{*}{ Asesoris kapitan } & & $\begin{array}{ll}\text { - } & 7 \text { ( } 7 \text { orang } \\
\text { kapitan/prajurit }) \\
\text { - } \quad 7 \text { batas pewarnaan }\end{array}$ & Bola, kurva tertutup \\
\hline & & & $\begin{array}{ll}- & 7 \text { ( } 7 \text { orang } \\
& \text { kapitan/prajurit }) \\
-\quad 7 \text { batas pewarnaan }\end{array}$ & Kurva tertutup \\
\hline & & & $\begin{array}{l}\text { - } 7 \text { (7 orang kapitan/ } \\
\text { prajurit) } \\
\text { - } 7 \text { batas pewarnaan }\end{array}$ & Kurva tertutup \\
\hline
\end{tabular}

Berdasarkan hasil temuan aktivitas adat cakalele (aksesoris) di atas bahwa terdapat penggunaan konsep matematika secara universal dilakukan oleh masyarakat adat Suku Nuaulu, yaitu berkaitan dengan hitungan, geometri, pengukuran, dan lan-lain. Hal ini senada dengan yang dikemukakan oleh Bishop tentang aktivitas matematika secara universal yang selanjutnya dikategorikan sebagai karakteristik etnomatematika dengan penjelasannya [12]. Dari penelitian ini dapat dinyatakan bahwa terdapat enam karakteristik dari etnomatematika, yaitu Counting, Locating, Measuring, Designing, Play, dan Explaining.

\section{KESIMPULAN}

Berdasarkan uraian tersebut di atas maka dapat disimpulkan bahwa pada simbol tarian adat cakalele Suku Nuaulu memuat karakteristik etnomatematika, yaitu menghitung (penjumlahan, perkalian, pembagian, dan lain-lain) terdapat pada para pelaku cakalele dan aksesoris yang digunakannnya, pengukuran terdapat pada kain berang yang dipakai oleh para pelaku adat; merancang terdapat pada aksesoris-aksesoris yang dipakai oleh para pelaku adat; permainan terdapat pada tarian cakalele sendiri; menjelaskan terdapat pada cerita tarian cakalele dan pendukungnya; dan keruangan terdapat pada tempat pelaksanaan tarian cakalele.

\section{DAFTAR PUSTAKA}

[1] A. Abdullah, "Ethnomathematics in Perspective of Sundanese Culture," Journal on Mathematics Education, Vols. Vol. 8, No. 1, pp. 1-16, Januari 2017.

[2] A. Küçük, "Ethnomathematics in Anatolia (Turkey: Mathematical Thoughts in Multiculturalism," Revista Latinoamericana de Etnomatemática, Vol. 7, No. 1, pp. 171-184, 2013.

[3] B. Reviews and A. Bishop, "Ethnomathematics - Challenging Eu- rocentrism in Mathematics Education," 


$$
\text { 1994, pp. 146-148. }
$$

[4] B. Barton and R. M. Frank, "Mathematical Ideas and Indigenous Languages," Sociocult. Res. Math. Educ. An Int. Perspect, pp. 135-140, 2001.

[5] Chatarina Febriyanti, Rendi Prasetya, Ari Irawan, "Etnomatematika pada Permainan Tradisional Engklek dan Gasing Khas Kebudayaan Sunda," Barekeng, Jurnal Ilmu Matematika dan Terapan, Vol. 12 No. 1, pp. 1 - 6, Maret 2018.

[6] C. Heather, "Success with Mathematics," New York: Routledge taylor and Francis Group, 2003.

[7] D. C. Orey and M. Rosa, "Ethnomathematics: Teaching and Learning Mathematics from a Multicultural Perspective," J. Math. Cult., Vols. Vol. 1, No.1, pp. 57-78, May 2006.

[8] G. F. Gilmer, ““'Ethnomathematics An African American Perspective On Developing Women In Mathematics," [Online]. Available: http://etnomatematica.org/articulos/Gilmerl.pdf. [Accessed 28 September 2018].

[9] J. P. Spradley, "The Ethnographic Interview, terjemahan Indonesia: Metode Etnografi oleh: Misbah Zulfa Elisabeth", Yogyakarta: Tiara Wacana, 2007.

[10] J. W. Creswell, "Educational Research: Planning, Conducting, and Evaluating Quantitative and Qualitative Research (4rd ed.)," Thousand Oaks, CA, Sage, 2012, pp. 238-241.

[11] J. W. Creswell, "Research Design: Qualitative, Quantitative, and Mixed Method Approach," California: SAGE Publication, 2009.

[12] J. W. Creswell., "Research design : qualitative, quantitative, and mixed methods approaches / John W. Creswell". — 4th ed, Vol. 136, No. 1., SAGE, 2014.

[13] M. Ascher, "Malagasy Sikidy: A Case in Ethnomathematics," Historia Mathematica 24, Vol. Article No. HM972159, pp. 376-395, 1997.

[14] M. W. Yusuf, I. Saidu, and A. Halliru, "Ethnomathematics (A Mathematical Game in Hausa Culture)," Int. J. Math. Sci. Educ. (C) Technomathematics Res. Found, 2010.

[15] P. Sopamena, "Etnomatematika Masyarakat Maluku Tengah Dan Kota Ambon Dalam Menjalani Kehidupan Sehari-Hari: Pemikiran Matematika dalam Multikulturalisme," Jurnal Integral Matematika dan Pembelajaran, Vol. 2, No. 2, pp. 1-20, 2016.

[16] T. Hammond, "Ethnomathematics : Concept Definition and Research Perspectives," A thesis submitted to the Graduate Faculty in Anthropology, Columbia University, New York, 2000.

[17] U. D’Ambrosio, "Ethnomathematics: Link Between Traditions and Modernity," Roterdam- Netherlands: sense Publisher, $2001 b$.

[18] U. D'Ambrosio, "Ethnomathematics and Its Place in the History and Pedagogy of Mathematics," Learn. Math., Vols. Vol. 5, No. 1, pp. 44-48, 1985.

[19] W. Handoko, "Asal-Usul Masyarakat Maluku, Budaya dan Persebarannya: Kajian Arkeologi dan Mitologi," Kapata Arkeol., Vols. Vol. 3, No. 5, pp. 1-27, 2007.

[20] W. S. Dominikus, "Etnomatematika Suku Adonara di Nusa Tenggara Timur,” Universitas Negeri Malang, Disertasi tidak dipublikasikan, Malang, 2017.

[21] Y. d'Entremont, "Linking Mathematics, Culture and Community," Procedia - Soc. Behav. Sci., Vol. 174, No. 1999, pp. 2818-2824, 2015. 
